Ivan T. Milošević

Visoka turistička škola

$811.111 ' 367.332 .3$

strukovnih studija, Beograd

$811.163 .41^{\prime} 367.332 .3$

ДОИ

https://doi.org/10.18485/analiff.2016.28.1.16

\title{
SUPROTSTAVLJANJE I PRIBLIŽAVANJE ZNAČENJA FRAZNIH GLAGOLA SA PARTIKULAMA SUPROTNOG ZNAČENJA IN-OUT I ON-OFF U SAVREMENOM ENGLESKOM JEZIKU
}

\begin{abstract}
Rad je posvećen engleskim fraznim glagolima sa partikulama suprotnog značenja in-out i on-off. Konkretnije, u radu se ispituju složeni međusobni značenjski odnosi koji se uspostavljaju između posmatranih jezičkih jedinica. Podsticajni okvir za ovo istraživanje pruža kognitivna semantika na osnovu čijih teorijsko-metodoloških postulata moguće je objasniti motivisanost osnovnih značenja kao i dalja nadovezivanja značenja unutar polisemičke strukture fraznih glagola. Na tim osnovama opisuju se različite vrste suprotstavljanja i približavanja značenja između fraznih glagola sa partikulama in, out, on i off i utvrđuju se vrste motivisanosti značenja koje su posledica delovanja različitih kognitivnih mehanizama: slikovnoshematskih transformacija, pojmovne metonimije i pojmovne metafore.
\end{abstract}

Ključne reči: frazni glagoli, partikule suprotnog značenja in-out i on-off, suprotstavljanje značenja (antonimija), približavanje značenja (sinonimija), motivisanost značenja, kognitivni mehanizmi, slikovne sheme SADRŽAVANJA i NOŠENJA

\section{Uvod}

Predmet ovog rada jesu značenjski odnosi fraznih glagola u savremenom engleskom jeziku koji sadrže partikule suprotnog značenja, na primeru fraznih glagola sa partikulama in-out i on-off. Naime, većina govornika engleskog jezika uzima zdravo za gotovo činjenicu da leksička jedinica in ima suprotno značenje od out, i leksička jedinica on suprotno značenje od off, kao što je to slučaj u sledećim primerima: He threw the ball in, but the lady immediately threw it out; We turnd the lights on, but the father turned them off. Međutim, kako Lindner (1982: 305) ističe, ovako 
postavljeni odnosi između gore navedenih leksičkih jedinica predstavljaju isuviše pojednostavljeno tumačenje. Ako, na primer, in i out imaju suprotno značenje u svim jezičkim upotrebama, bilo bi očekivano da i frazni glagoli turn in i turn out u rečenicama, They turned in their homework papers i Everything turned out okay, takođe imaju suprotno značenje, nego se, štaviše, čini da značenja fraznih glagola u prethodnim primerima ne samo da nisu suprotna, već izgledaju prilično nepovezana. Da stvar bude još složenija, postoje slučajevi gde ovi navodni parovi partikula suprotnog značenja (in-out, on-off) kao sastavni delovi fraznih glagola imaju gotovo isto značenje, te u nekom smislu možemo smatrati da stoje u sinonimijskom odnosu (He filled in an application form, He filled out an application form i When I was a student, I lived off bread and cheese, She was living on fruit and raw vegetables). Ovi slučajevi su već dovoljno indikativni pokazatelji tvrdnje da frazni glagoli koji sadrže partikule suprotnog značenja ispoljavaju veoma složene međusobne značenjske odnose, što je, kao što ćemo kasnije videti, u direktnoj korelaciji sa transformacijama slikovnih shema i vrstom motivisanosti nadovezivanja značenja u polisemičnoj strukturi fraznog glagola. Drugim rečima, zahvaljujući polisemičnoj strukturi posmatranih fraznih glagola koja presudno izvire iz pojmovnoznačenjske strukture sastavnih partikula (in, out, on i off), frazni glagoli koji sadrže partikule suprotnog značenja ispoljavaju složene međusobne značenjske odnose, u zavisnosti od vrste motivisanosti nadovezivanja značenja koja leži u osnovi polisemične strukture fraznih glagola. Što se tiče vrste značenjskih odnosa koji se ispituju, u ovom radu naglasak je stavljen na dva tipa značenjskih odnosa: antonimiju, odnosno, suprotstavljanje značenja, i sinonimiju, to jest, približavanje značenja posmatranih fraznih glagola.

Građa za ovo istraživanje zasniva se na dva ključna izvora, specijalizovanom rečniku, Oxford Phrasal Verbs, Dictionary for Learners of English, 2nd edition (2006) i elektronskom korpusu engleskog jezika British National Corpus $(B N C)^{1}$. Korpus na kome je izvršeno ovo istraživanje obuhvata 1112 fraznih glagola sa partikulama in, out, on i off, zabeleženih u gore navedenom rečniku, sa ukupno 2393 značenja. Zbog obima i prirode

1 Iza primera preuzetih iz rečnika (Oxford Phrasal Verbs, Dictionary for Learners of English) navodimo skraćenicu OXD, dok se iza primera preuzetih iz elektronskog korpusa engleskog jezika (British National Corpus) nalazi skraćenica BNC. 
SUPROTSTAVLJANJE I PRIBLIŽAVANJE ZNAČENJA FRAZNIH GLAGOLA SA PARTIKULAMA SUPROTNOG ZNAČENJA IN-OUT I ON-OFF U SAVREMENOM ENGLESKOM JEZIKU

naše analize, primeri su u radu navođeni selektivno sa ciljem adekvatnog ilustrovanja opisanih vrsta značenjskih odnosa između posmatranih fraznih glagola.

\section{Teorijsko-metodološki okvir}

Teorijsku osnovu ovog rada predstavlja kognitivna semantika koja je potekla iz sada već klasičnih studija Lakoff/Johnson (1980), Talmy (1983), Lakoff (1987), Langacker (1987), Johnson (1987) i Taylor ([1989] 2003). Jedno od važnijih stanovišta na kojima počiva kognitivna semantika, a u neposrednoj vezi sa značenjskom strukturom polisemičkih leksičkih jedinica, predstavlja pojam motivisanosti značenja - pravci proširivanja značenja su pojmovno i iskustveno motivisani, pri čemu se motivisanost ne može predvideti, ali se može objasniti. Drugim rečima, značenja leksema, posmatrana kroz teorijsko-metodološki okvir kognitivne semantike, nisu proizvoljna, već su motivisana. Kao što smo u uvodu ovog izlaganja implicitno naglasili, frazni glagoli predstavljaju jezičke jedinice koje ispoljavaju visok stepen polisemičnosti, pri čemu se motivisanost njihove polisemičke strukture može objasniti uz pomoć teorijskog aparata kognitivne semantike. U slučaju fraznih glagola sa partikulama suprotnog značenja in-out i on-off, na motivisanost njihovih osnovnih značenja presudno utiču slikovne sheme SADRŽAVANJA (in i out) i NOŠENJA (on i off) koje leže u osnovi njihovih pojmovno-značenjskih struktura ${ }^{2}$. Da se podsetimo, slikovne sheme (image schemata) predstavljaju organizovanje čovekovog iskustva u mentalne obrasce, o čemu temeljito svedoči Johnson (1987). One predstavljaju iskustvene, utemeljene i prepojmovne strukture koje postoje i u jeziku i u mišljenju. Stoga, i u slučaju shema sADRŽAVANJa i NOŠENJA možemo govoriti o specifičnim pojmovno-jezičkim strukturama iz kojih izviru značenja fraznih glagola sa partikulama in i out sa jedne strane, i on i off sa druge. Različita prostorna i neprostorna značenja ovih fraznih glagola mogu se delimično objasniti pomoću pojma profilisanja - deskriptivnog sredstva koje podrazumeva naglašavanja odnosa između određenog pojma i pojmovnog domena na osnovu koga se taj pojam ra-

2 U našoj kognitivističkoj praksi, shemama SADRŽAVANJA i NOŠENJA bave se sledeće studije: Klikovac (2000) - SADRŽAVANJE, Klikovac (2007) - NOŠENJE i Radenković (2011) - NOŠENJE. 
zume (Langacker, 1987), odnosno, na osnovu pojmova trajektora (primarnog objekta izdvojenog za primarni fokus) i orijentira (referentnog pojma) u okviru različitih prostornih scena (Talmy, 1983). S obzirom na činjenicu da se u našem radu bavimo shemama SADRŽAVANJA i NOŠENJA, mi ćemo, umesto termina trajektor i orijentir, koristiti termine SADRŽANI OBJEKAT (SO) i SADRŽATELJ (s) i NOŠENI OBJEKAT (NO) i NOSITELJ (N). Dalje nadovezivanje i ulančavanje značenja u okviru polisemičke strukture posmatranih fraznih glagola može se objasniti delovanjem brojnih kognitivnih mehanizmima koji leže u osnovi proširenja značenja kao što su: transformacije slikovnih shema, pojmovna metafora i pojmovna metonimija. Sa druge strane, motivisanost značenja fraznih glagola može biti posledica semantičke interakcije između sastavnog glagola i sastavne partikule.

Što se tiče proučavanja značenjske strukture partikula u engleskom jeziku na teorijskim osnovama kognitivne semantike, koja u prvi plan ističe motivisanost polisemije ovih jezičkih jedinica, možemo izdvojiti veliki doprinos sledećih studija: Brugman (1981) - proučava značenjsku strukturu leksičke jedinice over, Lindner (1981) - ispituje značenja engleskih fraznih glagola sa partikulama out i up, Yeagle (1983) - utvrđuje semantikču strukturu leksičke jedinice off, i konačno, Lakoff (1987: 416-461) - ispituje polisemičnu strukturu engleske lekseme over predstavljajući je kao zrakastu kategoriju prototipske strukture. U kontekstu značenjskih odnosa fraznih glagola koji sadrže partikule suprotnih značenja, istraživanje koje sprovodi Lindner (1982) na primerima partikula suprotnog značenja in-out i up-down, predstavlja dragocenu studiju i za naše istraživanje, pošto, na svojevrstan način, čini osnovu za ispitivanje značenjskih odnosa partikula i njihovih sastavnih fraznih glagola u ovom radu. Ova autorka ističe činjenicu da značenja partikula in i out, kao i partikula up i down, ne samo da nisu uvek suprotna, kao što misli većina govornika engleskog jezika, već ponekad mogu imati i sasvim ista značenja (npr. He filled in his registartion card, He filled out his registartion card). Štaviše, u radu se potvrđuju slučajevi kada ista partikula nosi suprotna značenja (npr. The stars are out and the lights are out), gde prvi primer ima značenje 'vidljivosti', dok drugi primer podrazumeva 'nevidiljivost'. Kao još jednu potvrdu složenih odnosa između partikula, Lindner navodi primere gde out i up imaju suprotno značenje (npr. Roll out the carpet and then roll it up).

Ovakav zamršeni splet odnosa u okviru pojmovno-značenjske strukture fraznih glagola sa partikulama in-out i on-off, čiji je osnovni produkt 
SUPROTSTAVLJANJE I PRIBLIŽAVANJE ZNAČENJA FRAZNIH GLAGOLA SA PARTIKULAMA SUPROTNOG ZNAČENJA IN-OUT I ON-OFF U SAVREMENOM ENGLESKOM JEZIKU

višeznačnost, predstavlja plodno tle za pojavu najrazličitijih značenjskih odnosa kojima se posmatrani frazni glagoli odlikuju i koje u jezičkoj realizaciji ispoljavaju. Što je stepen višeznačnosti unutar nekog jezikog segmenta veći, to su odnosi između jezičkih jedinica kojima se ona ispoljava složeniji i raznovrsniji.

\section{Značenjski odnosi između fraznih glagola sa partikulama in-out i on-off}

Ispitivanjem različitih značenjskih odnosa koji se uspostavljaju između fraznih glagola sa partikulama in-out i on-off, ustanovili smo da značenjski odnosi koji podrazumevaju približavanje i suprotstavljanje značenja između posmatranih leksičkih jedinica u značajnoj meri zavise od delovanja različitih kognitivnih mehanizama: slikovnoshematskih transformacija koje leže u osnovi sastavnih komponenata (na prvom mestu partikula), pojmovne metafore i pojmovne metonimije. Konkretnije rečeno, različita značenja posmatranih fraznih glagola koja izviru iz različitih shematskih struktura koje leže u osnovi njihovih sastavnih partikula imaju za posledicu složene međusobne značenjske odnose. Na taj način uvideli smo da posmatrani frazni glagoli koji sadrže a) iste partikule, a različite glagole, b) različite glagole, a iste partikule, ili, c) različite glagole i različite partikule, ispoljavaju najraznovrsnije značenjske odnose u vidu približavanja i suprotstavljanja značenja, odnosno, razvijaju veoma složene sinonimijske i antonimijske odnose.

\subsection{Antonimija - suprotstavljanje značenja}

Kada je reč o antonimijskim odnosima koje posmatrani frazni glagoli sa partikulama in, out, on i off ispoljavaju, naše istraživanje je ustanovilo sledeća četiri slučaja: a) isti glagol, partikula suprotnog značenja, b) različiti glagoli, partikule suprotnog značenja, c) različiti glagoli, ista partikula i d) isti glagol, ista partikula.

a) Isti glagol partikula suprotnog značenja

Prvi slučaj obuhvata posmatrane frazne glagole koji se sastoje od istog sastavnog glagola i sastavne partikule suprotnog značenja. Tipično, 
sastavni glagol odnosi se na aktivnost ili radnju koja je neutralnog karaktera, dok suprotna značenja izviru isključivo iz sastavnih partikula, što za posledicu ima dominantno ili izrazito značenje partikule u ukupnom značenju celovitog fraznog glagola. Ta suprotna značenja rezultat su postojanja komplementarnih slikovno-shematskih transformacija u okviru temeljnih slikovnih shema (SADRŽAVANJA i NOŠENJA), koje profilišu suprotne procese. Drugim rečima, radi se o podshemama unutar semantičkih struktura dve partikule suprotnog značenja (in-out i on-off) koje imaju identičan pojmovni sadržaj, osim u jednom segmentu, smeru u kome se takvo profilisanje vrši - ulaženju/nalažnju so u s (in) nasuprot izlaženju/ nalaženju so izvan s (out), ili, nošenju/osloncu No (on) nasuprot odvajanju No od $N$ (off). Kao rezultat ovakvog pojmovnog odnosa, suprotstavljenost značenja fraznih glagola koji se sastoje od istog glagola i partikule suprotnog značenja temelji se na suprotnim značenjima sastavnih partikula.

- Primeri sa partikulama in i out

Tipičan primer prethodno opisanog pojmovnog odnosa sa istim glagolom i pojmovno-značenjski dominantnom partikulom predstavljaju kontrarni antonimi iz prostornog domena, get in : get out.

1) He ran to the car, got in and drove off. (OXD)

The car door opened and a tall man got out. (OXD)

Kao ilustracija ovog slučaja koji se realizuje u neprostornim (apstraktnim) domenima mogu poslužiti brojni kontrarni antonimi čija suprotstavljenost značenja izvire iz pojmovnih korelacija UKLJUČIVANJE U AKTIVNOST i ISKLJUČIVANJE IZ AKTIVNOSTI: leave in : leave out, count in : count out, cut in : cut out, deal in : deal out, opt in : opt out, rule in : rule out, i sl.

2) If you are going to the theatre, you can count me in. (OXD) You can enjoy those games, but you can count me out. (OXD)

- Primeri sa partikulama on i off

Naročito produktivnu grupu čine antonimijski parovi čije značenje izvire iz suprotstavljenih prostornih odnosa POKRIVANJA (ON) i OTKRIVANJA (OFF). U tipične primere spadaju brojni frazni glagoli kojima se označava aktivnost oblačenja i svlačenja odevnih predmeta: get on : get off, throw on : throw off, fling on : fling off, slip on : slip off i pull on : pull off. 
SUPROTSTAVLJANJE I PRIBLIŽAVANJE ZNAČENJA FRAZNIH GLAGOLA SA PARTIKULAMA SUPROTNOG ZNAČENJA IN-OUT I ON-OFF U SAVREMENOM ENGLESKOM JEZIKU

3) Hold on, I'll slip my coat on, then I'll be ready. (OXD)

Slip off your coat and I'll make some tea. (OXD)

b) Različiti glagoli partikule suprotnog značenja

Za razliku od antonimijskog odnosa uspostavljenog između fraznih glagola u čijem sastavu se nalaze isti sastavni glagoli i partikule suprotnog značenja, gde partikula ima dominantno značenje u odnosu na glagol, u ovom slučaju i sastavni glagol i sastavna partikula imaju, u najvećem broju slučajeva, podjednako značajan uticaj na motivisanost značenja fraznih glagola. Drugim rečima, obe sastavne komponente (i glagol i partikula) izrazito su dominante u procesu motivisanosti značenja jezičke jedinice koju sačinjavaju. Naime, semantička struktura obe sastavne komponente (i glagola i partikule), sadrži izražena slikovnoshematska obeležja koja podjednako profilišu ukupno značenje celovitog fraznog glagola. U tom smislu, dolazi do neke vrste pojmovnog preklapanja (conceptual overlap) ${ }^{3}$ između unutrašnjih semantičkih struktura sastavnog glagola i sastavne partikule, pri čemu je semantička struktura fraznog glagola rezultat međusobne pojmovno-semantičke interakcije pomenutih sastavnih komponenti. Na osnovu vrste antonimijskog odnosa koji frazni glagoli u ovom odeljku ispoljavaju, možemo ih svrstati u relacione antonime (directional opposites), o kojima svedoče Lyons (1977: 281-282), Cruse (1986: 223233) i Murphy (2003: 197).

- Primeri sa partikulama in i out

U domenu prostora, frazni glagoli put in i take out imaju suprotno značenje u velikom broju primera u kojima su so i s konkretni/prostorni entiteti (tipično predmeti). Semantičke strukture sastavnih delova prvog fraznog glagola, to put i in, pojmovno se preklapaju i profilišu korelaciju stavljanje jednog entiteta (so) u drugi (s); sa druge strane, sastavni delovi drugog fraznog glagola, to take i out, takođe se pojmovno preklapaju u kodiranju korelacije izvlačenja jednog entiteta (so) iz drugog (S).

3 Na moguću pojavu pojmovno-značenjskog preklapanja između sastavnog glagola i sastavne partikule unutar semantičke strukture fraznih glagola ukazuje Hampe (2005: 120) koji navodi sledeće: 'From a cognitive perspective, this purpoted semantic redundancy can be conceived of as a heightened amount of conceptual overlap since the particles serve to make explicit image-schematic dimensions already inherent in the event domains specified by the verbs and their respective complements.' 
4) 'No, I'm sure I put it in my apron pocket, but I can't have done it.' (BNC) Jack felt in his pocket and took out his keys. (OXD)

- Primeri sa partikulama on i off

Kao što to dole navedeni primeri sa relacionim antonimima put on i take off ilustruju, u semantičkoj strukturi partikule on i glagola to put sadržane su semantičke komponente sheme NOŠENJA, ili preciznije, podsheme POKRIVANJA. Drugim rečima, i glagol to put i partikula on impliciraju ostvarivanje kontakta između No (kaputa - coat) i N (čoveka koji ga nosi). Sa druge strane, i iz sastavnog glagola to take i iz partikule off izvire značenje odvajanja NO od N, odnosno, obe komponente doprinose ukupnom utisku gubitka kontakta i oslonca između NO i N, što implicira suprotan proces koji je iskazan fraznim glagolom put on.

5) Aren't you going to put your coat on? (OXD)

She took her coat off and hung it up. (OXD)

c) Različiti glagoli ista partikula

Treći slučaj koji nedvosmisleno potvrđuje složenost značenjskih odnosa koje ispoljavaju posmatrani frazni glagoli jesu frazni glagoli suprotnog značenja koji sadrže istu partikulu, a različite sastavne glagole. U našem korpusu posvedočeni su brojni takvi slučajevi sa partikulama out i off. Sa druge strane, čini se da frazni glagoli sa partikulama in i on ne kodiraju takve međusobne značenjske odnose, na osnovu činjenice da u korpusu nismo zabeležili nijedan slučaj koji bi to potkrepio.

- Primeri sa partikulom out

Na osnovu činjenice da se pojmovno-značenjski suprotne kategorije DOSTUPNOSTI i NEDOSTUPNOSTI mogu konceptualizovati kao S, frazni glagoli come out i go out mogu ispoljiti visok stepen suprotnosti značenja. U prvom slučaju, so (stars) koji izlazi iz s (nedostupnosti) postaje dostupan posmatraču. U drugom slučaju, so (the last star) koji izlazi iz s (dostupnosti) postaje nedostupan posmatraču ${ }^{4}$. U profilisanju ovakvih po-

4 O ovoj pojmovno-jezičkoj pojavi koja podrazumeva mogućnost da partikula out ujedno kodira značenje i dostupnosti i nedostupnosti nekog entiteta pogledu posmatrača, u zavisnosti od njegovog položaja u odnosu na sadržatelja, prvobitno svedoči Lindner (1981: 121-122). 
SUPROTSTAVLJANJE I PRIBLIŽAVANJE ZNAČENJA FRAZNIH GLAGOLA SA PARTIKULAMA SUPROTNOG ZNAČENJA IN-OUT I ON-OFF U SAVREMENOM ENGLESKOM JEZIKU

jmovnih odnosa učestvuju i sastavni glagoli čija se semantička struktura - deiktičko to come (doći) implicira dostupnost, dok deiktičko to go (otići) implicira nedostupnost - poklapa sa pojmovnim scenama DOsTUPNOSTI so posmatraču i NEDOSTUPNOSTI SO posmatračus.

6) One evenening the stars came out and the whole sky shone as clear as polished jet. (BNC)

Even the last star went out. (BNC)

- Primeri sa partikulom off

U svim zabeleženim pimerima sa partikulom off, frazni glagoli sa istom partikulom profilišu dva suprotna temeljna principa: početak i završetak/ prekidanje aktivnosti, radnje ili događaja. Ilustracije radi, pogledajmo sledeći slučaj. U okviru pojmovnog domena DOGAĐAJA, frazni glagol kick off kodira značenje početka, dok frazni glagol finish off kodira značenje završetka.

7) The tour kicks off with a concert in Nottingham. (OXD)

The concert finished off with the band's latest hit. (OXD)

d) Isti glagol ista partikula

Konačno, u korpusu je zabeležen jedan, na prvi pogled, neobičan slučaj u kome dva različita značenja jednog istog fraznog glagola kodiraju suprotno značenje, što predstavlja primer jezičkog fenomena'autoautonimije': throw out. Ovaj slučaj se temelji na postojanju pojmovno-značenjske opozicije između pojmova DostupNostı i NEDOSTUPNOSTI koja izvire iz složene pojmovno-značenjske strukture partikule out. U prvom primeru, SO (a few ideas) postaje dostupan posmatraču, dok u drugom so (ideas) prestaje da bude dostupan posmatraču.

- Primeri sa partikulom out

8) She threw out a few ideas for us to consider. (BNC)

The institute is building a pilot coal pipeline at the Kuzbas coal fields, and is throwing out ideas such as container transport by pipeline for the future. (BNC)

5 Drugim rečima, sematičke strukture ovih sastavnih glagola upućuju na pojmove adlativnosti (to come) i ablativnosti ( to go). 


\subsection{Sinonimija - približavanje značenja}

Što se tiče približavanja značenja koje se uspostavlja između posmatranih fraznih glagola sa partikulama in, out, on i off, naša analiza je utvrdila sledeća tri slučaja: a) različiti glagoli, ista partikula, b) isti glagol, partikula suprotnog značenja i c) isti glagol, različita partikula nesuprotnog značenja.

a) Različiti glagoli ista partikula

Frazni glagoli koji spadaju u ovu grupu mogu se označiti kao kognitivni sinonimi koji podrazumevaju da je odnos između dve lekseme definisan iz perspektive iskaza u kojima se javljaju istinosni uslovi (truth conditions). Naime, kako Cruse (1986: 88) navodi, dve lekseme (X i Y) mogu se smatrati kognitivnim sinonimima ako (i) su X i Y sintaksički identični i (ii) ako bilo koja gramatička, deklarativna rečenica koja sadrži X ima ekvivalentne istinosne uslove kao i neka druga rečenica koja je identična prvoj rečenici sa jednim izuzetkom, a to je da je X zamenjen sa Y. Na primer, u kognitivne sinonime možemo ubrojati par violin i fiddle jer ove lekseme ne mogu da sadrže različite istinosne uslove - He plays the violin very well i He plays the fiddle very well, i podrazumevaju da je jedan (sinonim) nužna logička posledica drugog i obrnuto (mutual entailment). Kako rezultati naše analize potvrđuju, jedan frazni glagol najčešće ima jedan kognitivni sinonim (npr. deal in $\approx$ cut in, keep out $\approx$ stay out, turn on $\approx$ switch on, nod off $\approx$ doze off, itd.). Međutim, izvestan broj fraznih glagola, u svojim različitim značenjima, može imati dva, tri, čak i više kognitivnih sinonima, što je rezultat postojanja različitih slikovnoshematskih transformacija (podshema) i različitih neprostornih pojmovnih domena koje te podsheme strukturiraju unutar semantičke strukture partikule on.

- Primeri sa partikulom on

U cilju ilustrovanja prethodne tvrdnje, navešćemo primer fraznog glagola put on koji, na osnovu primera posvedočenih u našem korpusu, čak u svojih sedam različitih značenja koja izviru iz različitih podshema slikovne sheme NOŠENJA koja leži u osnovi semantičke strukture ovog fraznog glagola, ima različite kognitivne sinonime ${ }^{6}$. U prvom pri-

$6 \quad$ Naglasimo da su svi primeri sa fraznim glagolom put on originalno preuzeti iz korpusa, dok rečenice sa preostalim sinonimnim fraznim glagolima (npr. get on, 
SUPROTSTAVLJANJE I PRIBLIŽAVANJE ZNAČENJA FRAZNIH GLAGOLA SA PARTIKULAMA SUPROTNOG ZNAČENJA IN-OUT I ON-OFF U SAVREMENOM ENGLESKOM JEZIKU

meru, imamo značenje pokrivanja u značenju 'oblačenja odevnog predmeta' (put on $\approx$ get on); u drugom slučaju imamo značenje 'aktiviranje električnih uređaja' koje izvire iz podsheme dostupnosti (put on $\approx$ switch on $\approx$ turn on); u trećem i četvrtom takođe imamo značenje dostupnosti koje se nadovezuje na prethodno u okviru apstraktnih domena MUZIKE i (put on $\approx$ stick on) i KUVANJA (put on $\approx$ get on $\approx$ stick on) kojima se opisuju aktivnosti 'puštanja muzike' i 'pripremanja obroka'; u petom slučaju, u ulozi N nalazi se apstraktni domen RASPOREDA/REDA VOŽNJE, pri čemu se, tipično, neko prevozno sredstvo konceptualizuje kao No (put on $\approx$ lay on); $\mathrm{u}$ šestom primeru imamo značenje dodavanja dela na celinu (put on $\approx$ stick on) u apstraktnom domenu PLAĆANJA (tipično se radi o cenama, računima i sl.); sedmo značenje beležimo u pojmovnom domenu KLAĐENJA (put on $\approx$ bet on), pri čemu se potencijalni dobitak ili pobeda one opcije na koju je klađenje izvršeno konceptualizuje kao oslonac.

9) Aren't you going to put your coat on? (OXD) Aren't you going to get your coat on?

10) Shall I put the light on? (OXD)

Shall I turn the light on?

Shall I switch the light on?

11) Do you mind if I put some music on? (OXD) Do you mind if I stick some music on?

12) I need to get home and put the dinner on. (OXD) I need to get home and get the dinner on. I need to get home and stick the dinner on.

13) They put on extra trains during the holiday period. (OXD) They lay on extra trains during the holiday period.

14) They can't just put an extra 20p on the price of cigarettes! (OXD) They can't just stick an extra 20p on the price of cigarettes!

turn on i sl.) nisu originalno preuzete iz korpusa, već su navedene u cilju ilustrovanja kognitivnih sinonima, što podrazumeva iskaze sa istinosnim uslovima. 
15) I've put $£ 10$ on Sultan’s Promise (= a horse) in the nex t race. $(\mathrm{OXD})$

I've bet $£ 10$ on Sultan’s Promise (= a horse) in the next race.

b) Isti glagol partikula suprotnog značenja

Ovaj slučaj obuhvata značenjske odnose uspostavljene između fraznih glagola koji sadrže isti sastavni glagol i partikulu suprotnog značenja (in : out i on : off) iz ugla sinonimije, što, u najmanju ruku, predstavlja, neobičnu jezičku pojavu. Kao što smo već posvedočili u odeljku o antonimiji gde smo analizirali frazne glagole sa istim sastavnim glagolom i različitom partikulom (npr. live in : live out, turn on : turn off, itd.), izvestan broj ovakvih primera formira antonimijske parove, što predstavlja uobičajenu jezičku pojavu, ako se u obzir uzme činjenica da se u njihovoj leksičkoj strukturi nalaze partikule suprotnog značenja. Međutim, parovi fraznih glagola poput live on i live off $\mathrm{u}$ primerima, She was living on fruit and raw vegetables. (OXD) i When I was a student I lived off bread and cheese. (OXD), ili tap in i tap out u primerima, Tap in your password. (OXD) i I picked up the phone and tapped out Joe's number. (OXD), ne samo da ne ukazuju na suprotno značenje, već, štaviše, označavaju gotovo isto značenje - 'živeti/preživljavati zahvaljujući nečemu', u prvom slučaju, i 'uneti/ukucati podatke u neki uređaj', u drugom slučaju - samim tim ističući činjenicu da se ovde radi o sinonimijskom značenjskom odnosu između pomenutih fraznih glagola. Na ovu pojavu upučuje Lindner (1982: 305) ilustrujući je sledećim primerima: They closed up the theater u odnosu na They closed down the theater, $\mathrm{i}$, He filled in his registration card nasuprot He filled out his registration card. Dalje u tekstu (1982: 315-316), ova autorka objašnjava razloge zbog kojih, na primer, leksički par fill in : fill out, stoji u sinonimijskom odnosu. Naime, ovo je moguće ako se iste ili uporedive pojmovne scene mogu tumačiti dvojako, iz ugla pojmovne strukture partikule in ili iz ugla pojmovne strukture partikule out. Stoga, kada je u pitanju fill in, radi se o ubacivanju pisanog materijala (tipično reči) na neko prazno mesto, što je sadrženo u partikuli in, a u slučaju fill out, dodavanje pisanog materijala dovodi orijentir (registartion card) do potpunog, ispunjenog kanoničkog oblika/stanja, što profiliše partikula out.

- Primeri sa partikulama in i out 
SUPROTSTAVLJANJE I PRIBLIŽAVANJE ZNAČENJA FRAZNIH GLAGOLA SA PARTIKULAMA SUPROTNOG ZNAČENJA IN-OUT I ON-OFF U SAVREMENOM ENGLESKOM JEZIKU

U slučaju fraznih glagola tap in i tap out, koji znače 'unošenje informacija/podataka u neki elektronski uređaj pritiskom na dugme', približavanje značenja izvire iz sledećih pojmovnih odnosa: partikula in kodira značenje 'unošenja/ubacivanja podataka' pomoću prostorne scene ubacivanja so $u$ s, pri čemu se podaci (so) pojavljaju na ekranu/displeju tog uređaja; sa druge strane partikula out profiliše značenje 'vidljivosti/ dostupnosti podataka' koja je posledica prostorne scene izbacivanja so $u$ $S$, pri čemu se kao s konceptualizuje pojam NEVIDLJIVOST/NEDOSTUPNOSTI. Značenje oba frazna glagola dodatno motiviše pojmovna metonimija NAČIN ZA RADNJU koja izvire iz semantičke strukture sastavnog glagola (to tap).

16) He tapped in the code, then waited, knowing the signal was being scrambled through as many as a dozen sub-routes before it got to its destination. (BNC)

He knocked quickly, tapping out the code Madam Lundy had given $\operatorname{him} .(\mathrm{BNC})$

- Primeri sa partikulama on i off

Značenjski odnos sledećeg para sinonima feed on $\approx$ feed off rezultat je sledećeg pojmovnog odnosa: u slučaju prvog fraznog glagola, partikula on, označava 'izvor energije' (što je u metonimijskoj vezi sa hranom glagol to feed) koju No crpi iz N razume se kao oslonac, dok se u slučaju drugog, partikula off se odnosi na'crpljenje energije' razume kao 'odvajanja dela od celine' sa naglaskom na 'stalnost izviranja i toka energije'.

17) This bat feeds on fruit. (OXD)

The fleas' eggs are laid in the nest and once hatched the fleas feed off the young rabbits. (BNC)

c) Isti glagol partikula nesuprotnog značenja

Naša analiza potvrdila je postojanja približnih značenja između fraznih glagola čije je značenje u osnovi motivisano različitim slikovnim shemama - SADRŽAVANJA i NOŠENJA. Konkretnije rečeno, u sinonimijskom odnosu mogu se naći frazni glagoli sa partikuloma out i off sa jedne strane - npr. log out (of a computer sytem) i log off (a computer system), i partikulama in i on sa druge - npr. $\log$ in i log on. Napomenimo da je broj prim- 
era fraznih glagola sa partikulama out i off koji se nalaze u odnosu sinonimije daleko brojniji od primera sa in i on (zabeležena su samo dva primera). Ova brojčana prevaga može se objasniti daleko zastupljenijim preklapanjem pojmovno-semantičke strukture partikula out i off u odnosu na tek neznatno preklapanje pojmovno-semantičke strukture partikula in i on.

- Primeri sa partikulama out i off

Približavanje značenja fraznih glagola vote out $\approx$ vote off izvire iz činjenice da se institucije mogu konceptualizovati kao S ili kao N, pri čemu se članovi razumeju kao so ili No. Pomoću sadejstva metafora InSTITUCIJE SU S i INSTITUCIJE SU N sa jedne strane i metonimije ČLAN-GRUPA (konkretizacije opštije metonimije DEO-CELINA) sa druge, semantička komponenta 'isključivanja čoveka/osobe iz članstva u instituciji' razume se kao izdvajanje/vađenje dela (SO) iz celine (S) - u slučaju partikule out, ili odvajanje dela (NO) od celine (N) - u slučaju partikule off.

18) What will he do if he gets voted out? (OXD)

Parsons was voted off the Board. (OXD)

- Primeri sa partikulama in i on

Frazni glagoli clock in $\approx$ clock on, koji stoje u sinonimijskom odnosu, označavaju radnju/čin 'evidentiranja vremena otpočinjanja radnog procesa'. Prvi frazni glagol crpi značenje iz sadejstva metafore RADNO MESTO JE S (u kojoj je sadržana i metonimija UREĐAJ ZA KUCANJE KARTICA ZA RADNO MESTO), i metonimije POSEDNIK ZA POSEDOVANO (radnik za katicu). Sa druge strane, u profilisanju značenja drugog fraznog glagola učestvuju metafore PRISUSTVO JE KONTAKT i AKTIVNOSTI SU PUTANJE (Silvestre 2009: 233).

19) From the start there was no such thing as clocking in; Bernard would usually arrive at $7.30 \mathrm{am}$, sometimes earlier, and everyone else would be there y 8 am. (BNC)

We arrived and clocked on for the night shift. (OXD)

- Primeri sa partikulama in i off

Zahvaljujući raznovrsnosti slikovnoshematskih transformacija slikovnih shema SADRŽAVANJA i NOŠENJA, moguće je da različite podsheme unutar semantičke strukture različitih partikula motivišu približno ista 
SUPROTSTAVLJANJE I PRIBLIŽAVANJE ZNAČENJA FRAZNIH GLAGOLA SA PARTIKULAMA SUPROTNOG ZNAČENJA IN-OUT I ON-OFF U SAVREMENOM ENGLESKOM JEZIKU

značenja. Takvi slučajevi, a u vezi sa značenjem izolovanja, zabeleženi su i u našem korpusu, pri čemu jezičke realizacije pomenutog značenja izolovanja predstavljaju frazni glagolima sa partikulama in i off. (npr. fence in $\approx$ fence off $\mathrm{i}$ wall in $\approx$ wall off). Drugim rečima, veoma visok stepen približavanja značenja izvesnih fraznih glagola sa partikulama in i off potiče iz dve različite podsheme koje leže u osnovi sematičke strukure pomenutih partikula na koje se nadovezuje neprostorno značenje izolovanja. U prvoj podshemi, partikula in profiliše izolovanje so izvan $s$ koje izvire iz prostornog odnosa okruživanja so fizičkom preprekom, dok u drugoj partikula off profiliše izolovanje NO od N, što izvire iz prostorne scene izolovanja No fizičkom preprekom. Naravno, različite podsheme profililšu veoma različite procese i načine izolovanja jednog entiteta od drugog. U primerima sa in, naglašava se ostajanje so unutar granica s, sa ekplicitnim naglaskom na nemogućnost prvog entiteta da se 'oslobodi' i 'izađe' izvan granica S. U primerima sa off, izolovanje se profiliše kroz proces 'odvajanja' jednog dela entiteta (NO) od drugog (N) fizičkom preprekom, pri čemu se prvom entitetu onemogućava 'kontakt' sa drugim.

20) The grounds are fenced in by barbed wire. (OXD) We've fenced off the vegetable patch to stop rabbits from getting in. (OXD)

21) Apartment blocks wall in the playground completely. (OXD)

Part of the yard had been walled off. (OXD)

\section{Zaključak}

Kao što nalazi naše analize potvrđuju, engleski frazni glagoli sa partikulama suprotnog značenja in-out i on-off ispoljavaju složene antonimijske i sinonimijske odnose zavisno od vrste motivisanosti značenje u okviru njihove polisemične strukture. Tako složeni odnosi suprotstavljanja i približavanja značenja posledica su delovanja različitih slikovnih transformacija unutar shema SADRŽAVANJA (in-out) i NOŠENJA (on-off) koje presudno utiču na na motivisanost osnovnih značenja posmatranih fraznih glagola u sadejstvu sa pojmovnom metonimijom i metaforom sa jedne strane, i semantičke interakcije između sastavnog glagola i partikule unutar celo- 
vitog fraznog glagola sa druge. Naša analiza je potvrdila da se različite vrste suprotstavljanja značenja između posmatranih fraznih glagola mogu ispoljiti u sledećim slučajevima: a) isti glagol, partikula suprotnog značenja (npr. get in : get out) b) različiti glagoli, partikule suprotnog značenja (npr. put on : take off) c) različiti glagoli, ista partikula (npr. kick off : finish off) i d) isti glagol, ista partikula (throw out : throw out). Takođe, približavanje značenja zabeležili smo u sledećim slučajevima: a) različiti glagoli, ista partikula (npr. put on $\approx$ stick on $\approx$ get on) b) isti glagol, partikula suprotnog značenja (npr. live on $\approx$ live off) i c) isti glagol, različita partikula nesuprotnog značenja (npr. fence in $\approx$ fence off). Na kraju, na osnovu rezultata naše analize, koja je izvršena na primeru fraznih glagola sa partikulama suprotnog značenja in-out i on-off, možemo istaći značajan doprinos kognitivne semantike na polju ispitivanja semantičke strukture i utvrđivanja raznovrsnih međusobnih značenjskih odnosa fraznih glagola sa partikulama suprotnog značenja, što može predstavljati polazno stanovište za dalja semantička istraživanja ovih jezičkih jedinica u domenu različitih međusobnih značenjskih odnosa.

\section{Literatura}

Brugman, C. (1981). Story of Over. M.A. Thesis, University of California, Berkeley.

Cruse, D. A. (1986). Lexical Semantics. Cambridge University Press, Cambridge.

Hampe, B. (2005). When down is not bad, and up not good enough: A usage-based assessment of the plus-minus parameter in image-schema theory. Cognitive Linguistics 16 - 1, 115-146.

Johnson, M. (1987). The Body in the Mind: The Bodily Basis of Meaning, Reason and Imagination. Chicago: University of Chicago Press.

Klikovac, D. (2000). Semantika predloga - Studija iz kognitivne lingvistike. Beograd: Filološki fakultet.

Klikovac, D. (2007). Predloška značenja u nastavi srpskog jezika kao stranog: slučaj predloga $u$ i na. U zborniku: Srpski kao strani jezik u teoriji i praksi. Beograd: Filološki fakultet, Centar za srpski kao strani jezik, 47-63. 
SUPROTSTAVLJANJE I PRIBLIŽAVANJE ZNAČENJA FRAZNIH GLAGOLA SA PARTIKULAMA SUPROTNOG ZNAČENJA IN-OUT I ON-OFF U SAVREMENOM ENGLESKOM JEZIKU

Lakoff, G. (1987). Women, Fire and Dangerous Things. Chicago: Chicago University Press.

Lakoff, G./Johnson, M. ([1980] 2003). Metaphors We Live By. $2^{\text {nd }}$ edition. Chicago: University of Chicago Press.

Langacker, R. (1987). Foundations of Cognitive Grammar, Vol. I: Theoretical Prerequisites. Stanford: Stanford University Press.

Lindner, S. (1981). A Lexico-Semantic Analysis of English Verb-Particle Constructions with UP and Out. Ph.D. Thesis, University of California, San Diego.

Lindner, S. (1982). What goes up doesn't necessarily come down: The ins and outs of opposites. CLS 8: 305-323.

Lindstromberg, S. (2010). English Prepositions Explained. Amsterdam/ Philadelphia: John Benjamins Publishing Company.

Lyons, J. (1977). Semantics, Vol.I. Cambridge: Cambridge University Press.

Murphy, M. L. (2003). Semantic relations and the lexicon: antonymy, synonymy, and other paradigms. Cambridge: Cambridge University Press.

Nerlich, B., Todd, Z., Herman, V. and Clarke, D. D. (eds) (2003). Polysemy: Flexible Patterns of Meaning in Mind and Language. Berlin: Mouton de Gruyter.

Oxford Phrasal Verbs, Dictionary for Learners of English, 2nd edition (2006), Oxford University Press.

Palmer, F. R. (1981). Semantics. Cambridge: Cambridge University Press.

Radenković, J. (2011). Predloška realizacija slikovne sheme NOŠENJA u srpskom jeziku. Magistarski rad. Beograd: Filološki fakultet.

Silvestre Lopez, A. J. (2009). Particle Semantics in English Phrasal and Prepositional Verbs: The Case of In and On. Saarbrücken: VDM Verlag Dr. Müller.

Talmy, L. (1983). How Language Structures Space. In: Pick/Acredolo (eds.), 1983, 225-282.

Taylor, J. ([1989] 2003). Linguistic Categorization, 3rd edition. Oxford: Oxford University Press.

Yeagle, R. (1983). The Syntax and Semantics of English Verb-Particle Constructions with OFF: A Space Grammar Analysis. M.A. Thesis, Southern Illinois University, Carbondale. 
Ivan T. Milošević

Summary

\section{THE ANTONYMOUS AND SYNONYMOUS SEMANTIC RELATIONS BETWEEN THE PHRASAL VERBS CONTAINING OPPOSITE MEANING PARTICLES IN-OUT AND ON-OFF IN THE CONTEMPORARY ENGLISH LANGUAGE}

This paper is focused on the English phrasal verbs containing particles with opposite meaning, in-out and on-off. In particlular, this paper investigates the complexity of interdependent semantic relations which are formed between the linguistic units under examination. The theoretical framework for this research is provided by Cognitive Semantics whose theoretical and methodological postulates form the basis for the explanation of both the basic and extended meanings within the polysemic structure of the phrasal verbs. This framework provides the grounding for the description of different types of antonymous and synonymous semantic relations between the phrasal verbs containing particles in, out, on and off, as well as for the determination of different types of semantic motivation which result from various cognitive mechanisms: image schemas, the conceptual metonymy and the conceptual metaphor.

Key words: phrasal verbs, opposite meaning particles in-out and on-off, antonymous relations, synonymous relations, semantic motivation, cognitive mechanisms, containment and support image schemas 